\title{
The researches on the hunting in Brazil: a brief overview
}

Hugo Fernandes-Ferreira1 ${ }^{1 *}$ and Rômulo Romeu Nóbrega Alves²

\begin{abstract}
This article aims to realize a brief overview regarding researches involving hunting of wildlife in Brazil. We investigated which ethnicities, biomes and zoological groups were most studied, as well as current trends and prospects regarding this activity. The results show that although the number of publications is growing exponentially, the scenario is far from satisfactory. It is necessary to have mainly more analyses in both number and complexity involving biomass consumption, defaunation, wildlife management and hunting sustainability.
\end{abstract}

Keywords: Conservation, Ecology, Ethnobiology, Ethnozoology, Game Animals

\footnotetext{
1 Universidade Estadual do Ceará. Faculdade de Educação, Ciências e Letras do Sertão Central. Quixadá, Ceará State, Brazil.

2 Universidade Estadual da Paraíba. Departamento de Biologia. Campina Grande, Paraíba State, Brazil.
}

* Corresponding author. $\square$ E-mail address: fernandes.ferreira@uece.br

\section{INTRODUCTION}

Hunting of wildlife takes place throughout all regions of Brazil. Whether it is undertaken by indigenous, rural or urban communities it is considered a deeply rooted cultural practice. Although this practice is responsible for improving the diet of numerous traditional populations and can serve to control invasive species, overexploitation of animals is considered one of the principal causes of the drastic defaunation that Brazilian ecosystems have been experiencing (Fernandes-Ferreira 2014; Ramos et al. 2016; Sousa and SrbekAraújo 2017).

It clearly follows that understanding the techniques, purposes, and biodiversity involved in hunting and, especially, the impact of these activities is of fundamental importance to the conservation of wildlife. This work aims to provide a brief review of the published scientific literature on hunting of wildlife in Brazil. We investigated which ethnicities, biomes and zoological groups were most studied, as well as current trends and prospects regarding this activity. We discuss our analysis with the historical context related to these factors.

The survey was carried out by performing searches with virtual networks that share scientific information (peer-review articles, books and book chapters), such as Google Books, Google Scholar, Web of Science, 
Scopus, Scielo, Web of Knowledge, Biodiversity Heritage Library, Brasiliana USP and Brasiliana UFRJ, using the following keywords in both English and Portuguese: hunting, hunted, game, poaching and Brazil. We did not include grey literature in this analyzes.

\section{STUDIES PUBLISHED}

A total of 74 scientific publications involving the hunting of wild animals in Brazil were encountered for the period of 1936 to 2017. The earliest research regarding this subject was originally distributed in government publications that aimed to quantify the extent of regional and national commercial hunting (e.g. Aguirre 1936).

From an anthropological point of view, research on wildlife hunting experienced an increase beginning in the 1970s and continuing through the 1980 s, a period when the first articles with a zoological and conservation perspective appeared (Fernandes-Ferreira 2014). From the end of the 1980s and through the 1990s, studies on the impact of the removal of animal biomass using more complex methods for determining population density in situ began to dominate. These research trends continued, but with published works almost exclusively addressing the Amazon Region (e.g. Peres 1997). The first ecological analyses of hunting in the Atlantic Forest appeared only in the late 1990s and early 2000s (e.g. Cullen-Jr. 2001).

Figure 1 shows the accumulation of scientific publications from Aguirre (1936) to the present day, illustrating the considerable increase in publication frequency beginning in the 1980s, followed by a more gradual increase during the 1990s, and then a more rapid increase over the last 15 years.

The pronounced increase in the number of publications during the 1980s can be explained by a worldwide effort to measure the impact of hunting, which had already appeared in global media as a shocking practice (Fernandes-Ferreira and Alves 2014). In this context, works developed in the Amazon between the 1980s and 1990s provided a fundamental basis for the development of further research. From the first decade of the 21st century onward, the rapid increase towards an asymptote can be explained by a great elevation in the number of public universities, vacancies for teachers, courses and graduate scholarships in Brazil, which promoted, in almost all scientific contexts, a significant increase in academic production. Furthermore, this precipitated the establishment of new research groups, mainly in the Northeast Region, that focused on ethnozoology.

\section{BIOMES STUDIED}

Regarding the study areas, the last two decades experienced the most constant production of research involving several aspects of hunting of wild vertebrates in the Amazon (e.g. Ramos et al. 2016), Atlantic Forest (e.g. Sousa and Srbek-Araújo 2017), Caatinga (e.g. Alves et al. 2016a), Pantanal (e.g. Desbiez et al. 2011) and Pampas (Peters et al. 2012). Nevertheless, as Figure 2 testifies, a great disparity among the studied areas remains, with a strong predominance of research in the Amazon, followed by the Caatinga and Atlantic forest; relatively few publications addressed hunting in the Cerrado, Pantanal and Pampas.

The predominance of studies carried out in the Amazon Region can be explained by several factors. Since the 16th century, the interest of Jesuits, explorers, and researchers in the fauna of the Amazon, and its uses experienced an increase 


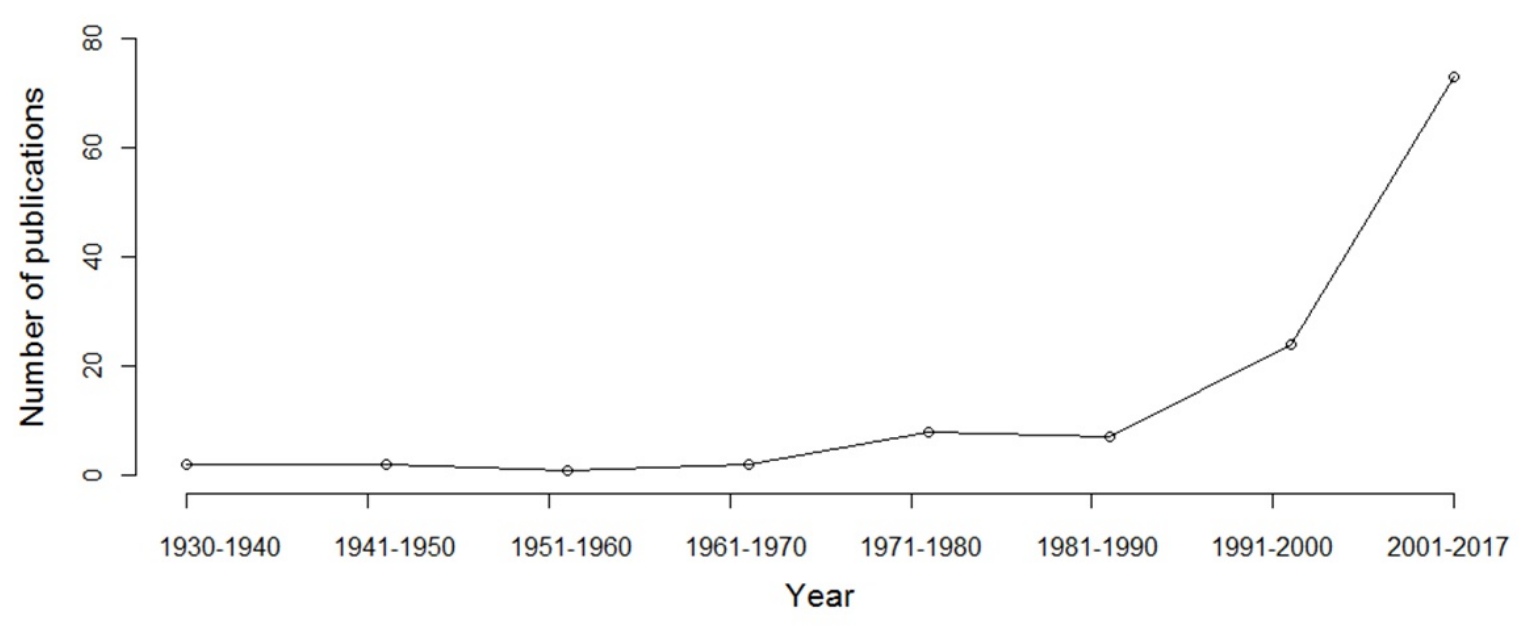

Figure 1. The number of scientific publications involving "hunting of wildlife" as a theme between 1936 and 2017

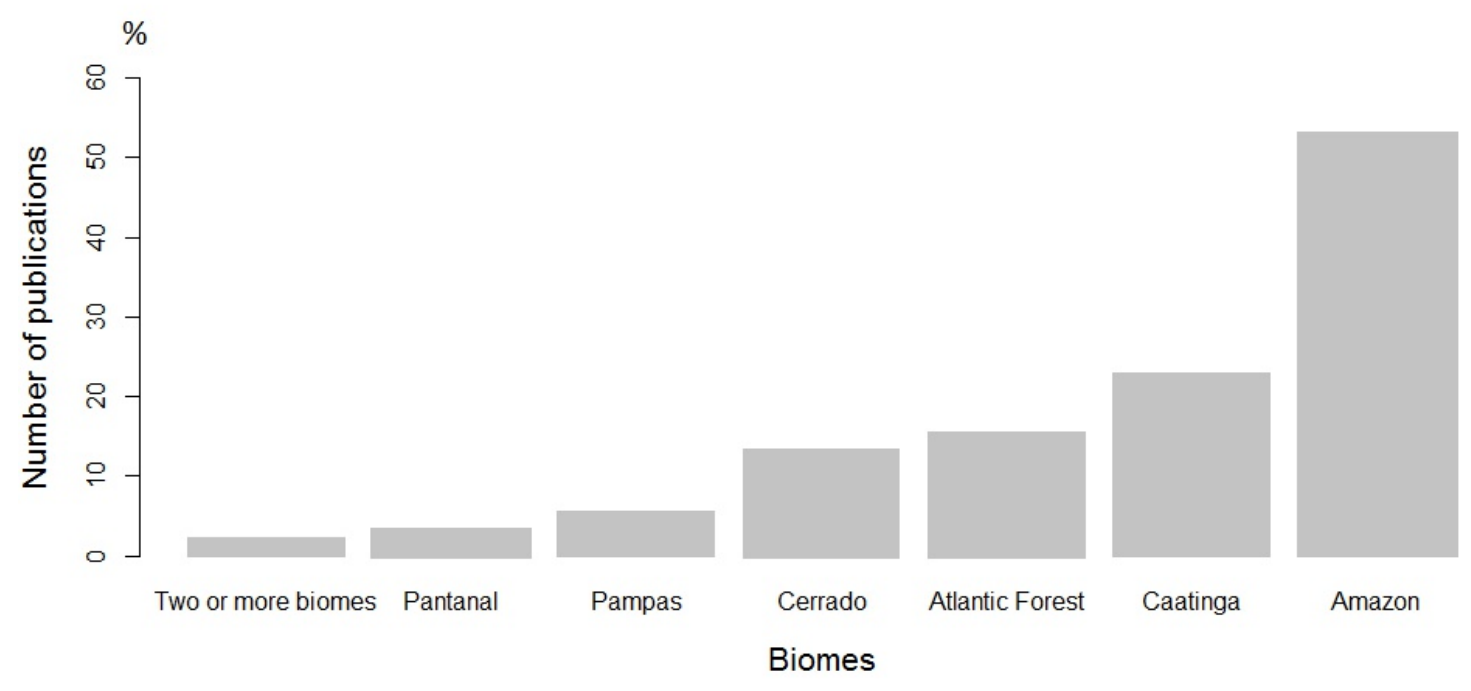

Figure 2. Percentage of scientific publications involving hunting of wildlife in Brazil according to the biomes

(Fernandes-Ferreira 2014). There was also the establishment of two large multidisciplinary research centers in the region, the former Museu Paraense de História Natural, now the Museu Paraense Emílio Goeldi (MPEG), founded in 1871 in Pará State, and the Instituto Nacional de
Pesquisas da Amazônia (INPA), founded in 1954 in Amazonas State. These institutions provided a technical framework of professionals with expertise in ecology, anthropology, sociology, history and archaeology, thus facilitating studies regarding the practice of hunting. Another 


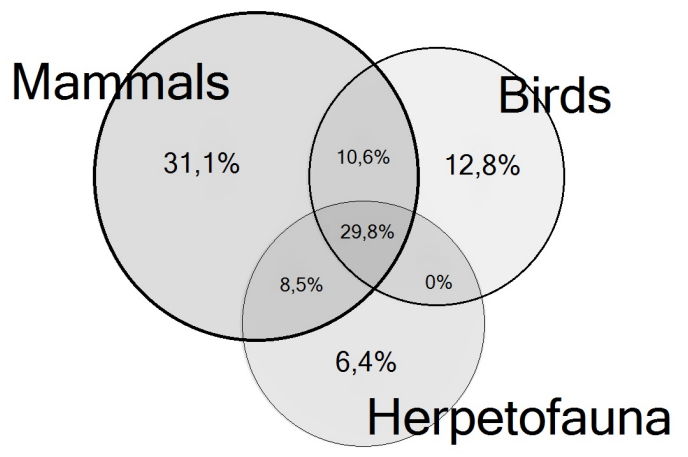

Figure 3. The percentage of publications addressing hunting of mammals, birds and reptiles and amphibians in Brazil

important reason for the greater amount of research in the Amazon is the relative ease by which hunting activities could be observed and studied there in relation to other biomes. Since the Amazon has a much lower population density than other regions of the country, it possesses a greater opportunity to monitor illegal hunting activity, which facilitates more efficient data collection. This advantage is further enhanced by studies undertaken within indigenous and extractive reserves, which are more common in the Amazon, and which are governed by a partial or total relaxation of laws regarding the taking of fauna.

In view of these considerations, the higher population density of the Caatinga and the greater difficulty in collecting data on illegal activities, seem to contradict this biomes status as second in research production. However, explanations for this scenario differ greatly from those presented above. First, most of the research in the Caatinga has been performed by a single research group. Second, publications regarding this biome began to increase in frequency only seven years ago, mainly by work carried out by research groups based at the Universidade Estadual da Paraíba, Universidade Federal da Paraíba, Universidade Federal Rural de Pernambuco e Universidade Regional do Cariri. Third, almost all investigations carried out in the Caatinga have been based on interviews or bibliographic surveys, which is much less complex than quantifying hunted biomass, for example.

\section{ETHNICITIES AND WILDLIFE GROUPS INVOLVED}

Among the ethnicities of the human communities involved in hunting, there is a considerable predominance of nonindigenous populations $(58 \%)$ when compared to indigenous (17\%) and mixed ethnicities (25\%).

This finding is easily explained by the greater density of rural populations in relation to indigenous tribes, especially in locations outside the Amazon. Traditional communities also tend to be less accessible due to the difficulties involved with the bureaucratic formalities of obtaining research licenses of the competent organizations such as Fundação Nacional do Índio (National Foundation of the Indigenous People), for example.

It was also found that most of studies were performed with mammals, which were present in $80.8 \%$ of the publications reviewed and the exclusive subject of $31.1 \%$ of them. Birds were the next most common, being present in $53.2 \%$ of the studies and exclusive to $12.8 \%$, followed by reptiles and amphibians together, which were present in $44.7 \%$ studies and exclusive to $6.4 \%$. The percentage of publications for each of these groups is shown in Figure 3. 


\section{RESEARCH TRENDS}

The latest trends in hunting research are generally along two main lines: ecological and ethnozoological. The first one has involved more quantitative analyses and have focused on the impact of the activity on the wildlife, such as comparisons between areas with high and low hunting pressures (e.g. Ramos et al. 2016), assessment of hunting sustainability (e.g. Mendonça et al. 2016), effects of defaunation (e.g. Sousa and Srbek-Araújo 2017), comparisons between removal of biomass by indigenous and non-indigenous communities (e.g. Mesquita and Barreto 2015), participation of traditional communities in management of subsistence hunting (e.g. Vieira et al. 2015) and synergistic effects between hunting and habitat loss (e.g. Constantino 2016). However, these types of investigations have only been undertaken in Atlantic Forest and, mainly, Amazonia. The second scope has a more descriptive character with focus on both wildlife and human aspects. There have been a substantial number of ethnozoological studies in the Caatinga biome, which have focused on addressing more embracing aspects of hunting techniques, purposes and game species (e.g. Alves et al. 2016), although there have been a few more specific studies, such as those related to the consumption of wild meat (e.g. Barboza et al. 2016) and trade in wild animals for pets (e.g. Souto et al. 2017).

In addition to these lines of research, several studies have addressed other specific topics in Brazil, such as the question of conflicts between human communities and predators of domestic animals (e.g. Engel et al. 2017); hunting of invasive species (Desbiez et al. 2011); police data on illegal hunting (e.g. Chagas et al. 2015), genetic analyses for the identification of wild meat (e.g. Silva-Neto et al. 2016) and legislation (Fernandes-Ferreira and Alves 2014).

\section{FINAL CONSIDERATIONS}

Literature analysis of research involving hunting in Brazil shows that although the number of publications is growing exponentially, the scenario is far from satisfactory. This condition is the result of two main factors: a lack of a broader coverage of studies and a scarcity of complex ecological analyses.

Considering the importance of hunting as a widespread activity throughout the country, involving biological, ecological, anthropological and sociological components, and often resulting in highly severe environmental impacts (Alves et al. 2016a; Constantino 2016; FernandesFerreira 2014), there is an urgent need to foster research in regions that have not yet been investigated, such as Pampas, Pantanal and Cerrado.

For the same reason, more quantitative analyses are needed, especially those involving rates of biomass withdrawal and consumption, impact of deforestation, management strategies and hunting sustainability. These are the most current trends for the studies conducted in the Atlantic Forest and, especially, the Amazon, and should be focus of research groups studying in the Caatinga, a region that already has an excellent descriptive basis regarding techniques, purposes and diversity of game animals. However, it is important to note that, even in the Amazon and Atlantic Forest, the number of studies is still quite scarce regarding the true complexity of the issue.

Understanding the details involved in the overexploitation of animal species at a 
national level and with the greatest quantity and quality of work possible is a fundamental step for the execution of effective conservation strategies in Brazil.

\section{REFERENCES}

Aguirre A (1936) A pesca e a Caça no Alto São Francisco. Rio de Janeiro, Ministério da Agricultura

Alves RRN, Feijó A, Barboza RRD, Souto WMS, Fernandes-Ferreira $H$, Cordeiro-Estrela $P$, Langguth A (2016) Game mammals of the Caatinga biome. Ethnobiology and Conservation 5:1-51

Souto WMS, Torres MAR, Sousa BFCF, Lima KGGC, Vieira LTS, Pereira GA, Guzzi A, Silva MV, Pralon BGN (2017). Singing for Cages: The Use and Trade of Passeriformes as Wild Pets in an Economic Center of the Amazon NE Brazil Route. Tropical Conservation Science 10:1-19.

Barboza RR, Lopes S, Souto W, FernandesFerreira H, Alves RRN (2016) The role of game mammals as bushmeat in the Caatinga, northeast Brazil. Ecology and Society 21:1-11

Chagas ATA, Costa MA, Martins APV, Resende LC, Kalapothakis E (2015) Illegal hunting and fishing in Brazil: a study based on data provided by environmental military police. Natureza \& Conservação 13:183-189

Constantino P (2016) Deforestation and hunting effects on wildlife across Amazonian indigenous lands. Ecology and Society 21:1-10

Cullen-Jr. L, Bodmer ER, Valladares-Padua C (2001) Ecological consequences of hunting in Atlantic forest patches, São Paulo, Brazil. Oryx 35:137-144

Desbiez ALJ, Keuroghlian A, Piovezan U, Bodmer RE (2011) Invasive species and bushmeat hunting contributing to wildlife conservation: the case of feral pigs in a Neotropical wetland. Oryx 45:78-83

Engel MT, Vaske JJ, Bath AJ, Marchini S (2017) Attitudes toward jaguars and pumas and the acceptability of killing big cats in the Brazilian Atlantic Forest: An application of the Potential for Conflict Index2. Ambio 2017:1-9

Fernandes-Ferreira H (2014) A caça no Brasil: panorama histórico e atual. $\mathrm{PhD}$ Thesis, Universidade Federal da Paraíba, João Pessoa, Brasil
Fernandes-Ferreira H, Alves RRN (2014) Legislation and media involving hunting of wild animals in Brazil: an historical and socioenvironmental perspective. Gaia Scientia 8:114

Mendonça WCDS, Marioni B, Thorbjarnarson JB, Magnusson WE, Silveira R (2016) Caiman hunting in Central Amazonia, Brazil. The Journal of Wildlife Management 80:1497-1502

Mesquita GP, Barreto LN (2015) Evaluation of mammals hunting in indigenous and rural localities in Eastern Brazilian Amazon. Ethnobiology and Conservation 4:1-14

Peres CA (1997) Primate community structure at twenty western Amazonian flooded and unflooded forests. Journal of Tropical Ecology 13:381-405

Peters FB, Roth PRO, Pereira MS, Piske AD, Christoff AU (2012) Aspectos da caça e perseguição aplicada à mastofauna na área de proteção ambiental do Ibirapuitã, Rio Grande do Sul, Brasil. Biodiversidade Pampeana 9:16-19

Ramos RM, Pezzuti JC, Vieira EM (2016) Age structure of the Vulnerable white-lipped peccary Tayassu pecari in areas under different levels of hunting pressure in the Amazon Forest. Oryx 50:56-62

Silva-Neto AA, Ferreira PB, Torres RA, Texeira RHF, Duarte JMB, Barbosa AC, Vargas RC, Garcia JE (2016) Diagnostic Cytochrome b gene profiles for the identification of paca (Cuniculus paca) bushmeat: implications for the monitoring of illegal hunting and wildlife trade. Brazilian Journal of Biology 76:55-58

Sousa JAC, Srbek-Araujo AC (2017) Are we headed towards the defaunation of the last large Atlantic Forest remnants? Poaching activities in one of the largest remnants of the Tabuleiro forests in southeastern Brazil. Environmental monitoring and assessment 189:197-206

Vieira MARM, Von Muhlen EM, Shepard GH (2015) Participatory monitoring and management of subsistence hunting in the Piagaçu-Purus reserve, Brazil. Conservation and Society 13:254-261

Received: 05 February 2017

Accepted: 01 June 2017

Published: 13 July 2017 